\title{
Pathology of Choanotenia infundibulum in the Intestine of Free Range Chickens from Hyderabad, Sindh, Pakistan
}

\author{
Zubeda Butt ${ }^{1 *}$, Azra A. Shaikh ${ }^{1,}$ Shakeel A. Memon ${ }^{2}$, Naeem \\ Tarique Narejo ${ }^{3}$ and Shaista Jalbani ${ }^{3}$ \\ 1Department of Zoology, University of Sindh, Jamshoro-76080, Pakistan \\ 2Government College \& Post Graduate Centre Hyderabad-71000, Pakistan \\ 3Department of Fresh Water Biology \& Fisheries, University of Sindh, Jamshoro \\ *Corresponding author email: Sonhdinawaz_butt@yahoo.com \\ Citation
}

Zubeda Butt, Azra A. Shaikh, Shakeel A. Memon., Naeem Tarique Narejo and Shaista Jalbani.

Pathology of Choanotenia infundibulum in the Intestine of Free Range Chickens from Hyderabad, Sindh, Pakistan. Pure and Applied Biology Vol. 4, Issue 2, 2015, pp 158-163.

Received: 23/01/2015

Revised: 22/04/2015

Accepted: 28/04/2015

\section{Abstract}

An attempt was made to investigate the pathological changes in the intestine of free range scavenging chickens infected with cestodes parasite Choanotenia infundibulum. For the purpose 100 birds (Gallus domesticus) were randomly purchased from different villages and local markets of district Hyderabad, Pakistan. Chicken were dissected and different parts of intestine were searched. Out of 100 birds 94 (89.5\%) were found infested with Choanotenia infundibulum. For histopathological examination different parts of infected intestine were fixed in Bouin's fixative for period of 24 hours. Paraffin embedded tissues were cut 5-6 micron thick and stained with hematoxylin and eosin $(\mathrm{H} \& \mathrm{E})$. Histopathological findings revealed sever damage including distortion, fusion, inflammation and destruction of architecture of muscular layers, villi and glands. It was concluded that high level of parasitic infestation cause severe health problems in birds and this can lead significant losses of poultry production.

Key words: Histopathology, chicken, intestine, Choanotenia infundibulum. Introduction

estimated to number about 14,000 million, The Poultry sector plays a vital role in national economy with an essential contributor of revenue by producing animal protein (meat and egg) to humans [1]. Poultry is one of the most important segments to rear the domesticated species and playing enormous role as profitable animal production enterprises [2].

Poultry is one the most organized group of the livestock which is producing an consisting mainly of chickens, ducks and turkeys. Approximately $80 \%$ of the poultry population is kept as free range poultry [3]. Chickens are generally raised in free range system, scavenging around the compound of house hold, feeding on locally available resources like earth worm, house hold refuse, insects residue from harvest, animal and human feaces etc [4]. 
Parasitic infestation causes severe health problems; slow growth, low egg production, low weight, anemia and mortality [5]. High parasitism in chicken has been reported from various part of the world [6-8] and also from Pakistan [9-12]. Keeping above in view the present study was designed to assess the parasitic infestation and their hazardous effects on poultry sector. Therefore this study provides guideline and awareness to improve better poultry management for minimizing the parasitic infections.

\section{Material and Methods}

\section{Collection of intestine samples}

Present study was conducted with the approval of the Advanced Studies and Research Board (ASRB) under the guidelines at Department of Zoology, University of Sindh Jamshoro, Pakistan. For the purpose live birds (Gallus domesticus) were collected from different locations of district Hyderabad and brought to the Parasitology Laboratory. After that collected birds were dissected and different parts of intestinal tract were carefully removed. These recovered intestines were examined under disectory microscope for parasitic infestation.

\section{Collection, Staining and Identification of Parasites}

The assorted parts of intestinal tract were examined for parasitic infestation by applying the method of Dharejo [13]. Various parasites were recovered from the different parts of infected intestine; jejunum, ileum and duodenum. It is important to relax and kill recovered parasites before fixation, which was done by putting them in saline water 15-30 minutes or by putting $70 \%$ alcohol drop by drop. There after killed parasites were potted in $70 \%$ alcohol and kept into small glass jars for further process of staining and identification. Preserved parasites were cautiously pressed between two glass slides and these slides were tie with thread by applying spongy pressure. The tied slides were kept in $70 \%$ alcohol for 48 hours. The pressed parasites were passed through graded alcohol series and stained with Borax carmine. Moreover parasites were washed in $70 \%$ alcohol and entirely dehydrated with $90 \%$ and absolute alcohol. The clove oil was used on the stained slides then cleared in xylol. The specimen permanently mounted in Canada balsam by putting them a glass cover slip.

\section{Results and Discussion}

In present studies 100 birds (Gallus domesticus) were examined out of which 94(89.5\%) were found infected with Choanotenia infundibulum. The parasites were identified on the basis of structural characteristics with the help of keys and literature $[14,15]$. The incidence of Choanotenia infundibulum infection from the chicken (Gallus domesticus) previously have been reported throughout world Butt et al., [16] from Pakistan reported 89.5\% ; Uho et al., [17] 36.7\%; Medjouel et al., [18] 11.8\%; Zahrani et al., [19] 12.38\%; Radfar et al., [20] 40.67\%; Hussen et al., [21] 13.7\%; Shahin et al., [22] 40.5\%; Eslami et al., [23] $8 \%$.

Histopathogical observations of the infected sections of intestine revealed severe tissue damage. Obviously, severity of lesions that aggravate by the parasite in the host tissue mainly depends on the parasite morphology, particularly its composition and size of the attachment organ. In the present findings histology of intestine of control chicken showing complete architecture of villi, muscular layer, crypt glands and lamina propria (Fig.2). Histopathological observations associated with Choanotenia infundibulum showed alteration, fusion, swelling and damaged muscular layers, villi and glands (Fig. 3 and 4). The deterioration of the glands was commonly observed. These findings are agreed with Butt et al., 
[24]. The infected intestine of chicken (Gallus domesticus) with Raillietina cesticillus showed architectural disintegration of villi and crypt glands and this also line with the results of Shaikh et al., [25]. The helminth parasites when they lodge in the inner walls of intestine with the help of their adhesive organs where they cause damage to the villi and also other layers of the intestine [26]. In present experimental study defused crypt glands associated with unidentifiable structure of crypt cells were observed (Fig.5). Their lumen were demonstrated completely congested (Fig.6). The helminthes adversely affects all layers of the intestine in kite (Milvus Migrus migrus) [27]. During Histopathological assessments inflammation in cells along with necrosis of the lamina propria was observed at the base of crypts (Fig. 7). These findings were in accordance with the results described by Muti-ur-

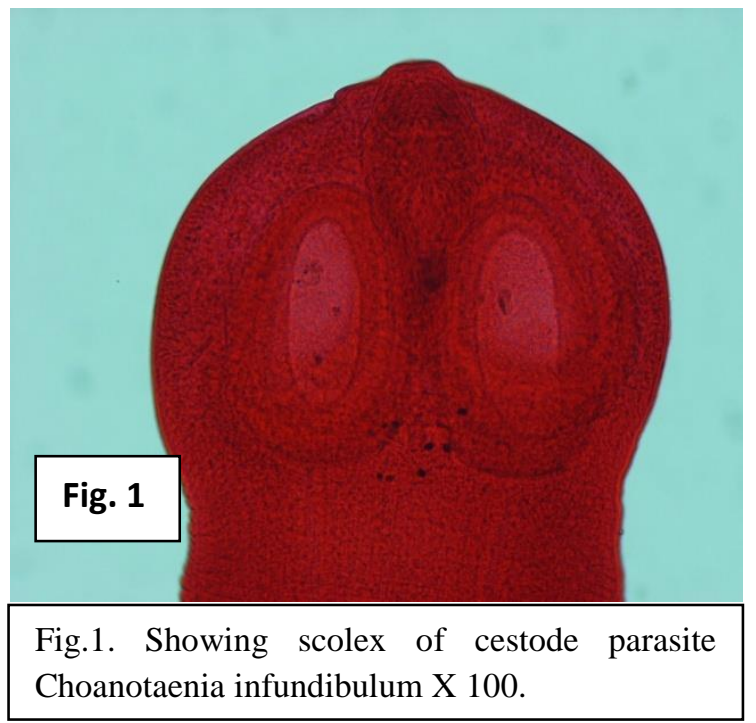

Rehman [28] in the intestine of eagle infected with Medioorhychus fatimae reported necrosis, inflammation and hyperplasia of glands. As a result of shrinkage muscular layer has been tear up showing fibers. Similar observations were made by other workers Laxma Reddy and Benarjee [26] who reported degeneration and hyperplasia of intestinal villi, necrosis and vacuolation of muscular mucosa. Sanil et al., [29] reported hyperplasia of intestinal villi, laminia propria, degeneration and necrosis of muscular layer.

\section{Conclusion}

This work strongly suggests that free range poultry is susceptible to high risk of parasitic infection and have high economic impact in the poultry production. Therefore, further investigations are needed to elucidate the economic and hygiene impact of parasitic infection on poultry reared in free range backyard system.

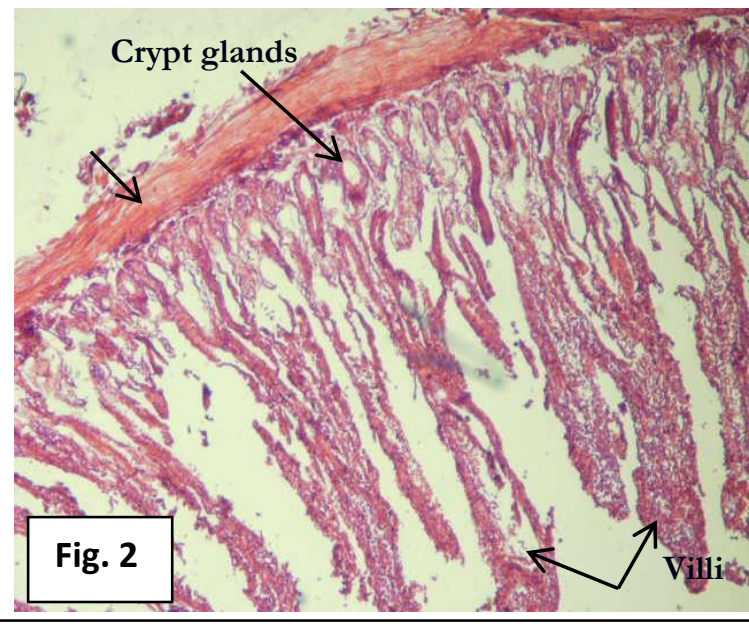

Fig.2. Showing over all non-infected intestine including muscular laver crvnt glands and villi X 200 

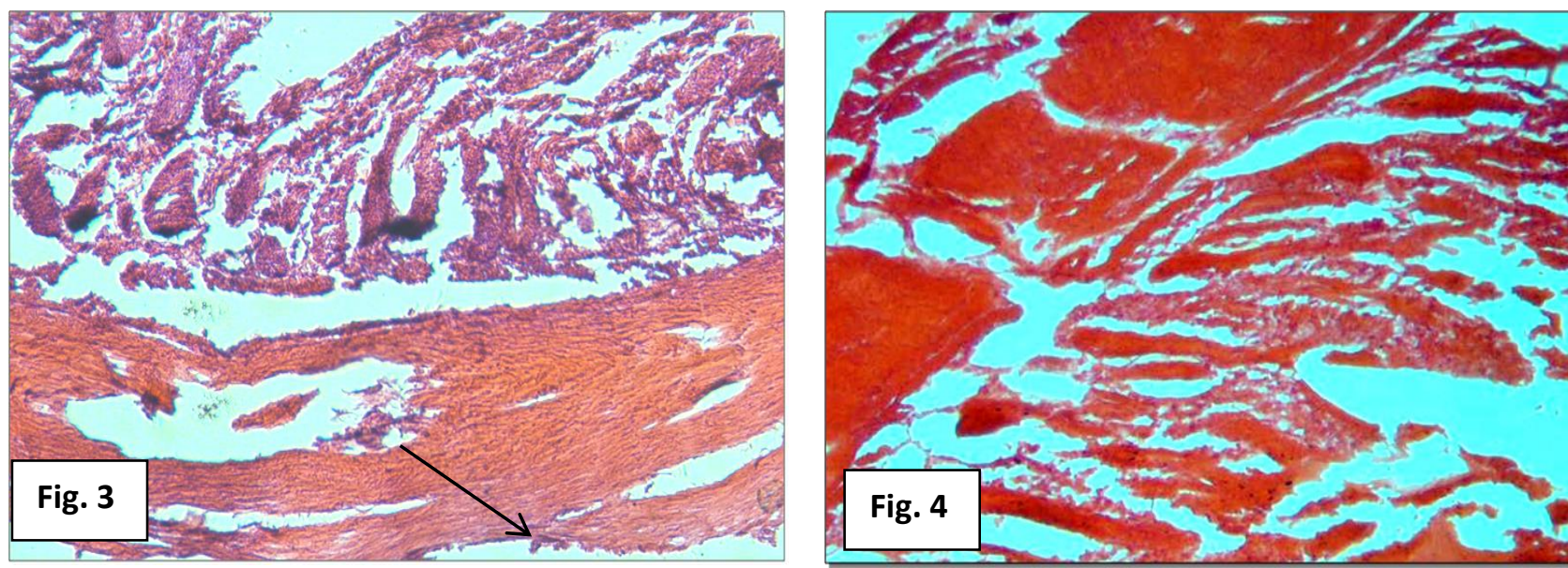

Fig.3-4. Section of infected intestine showing architectural disintegration: distortion, fusion of glands and gapes in the muscular layer X100.
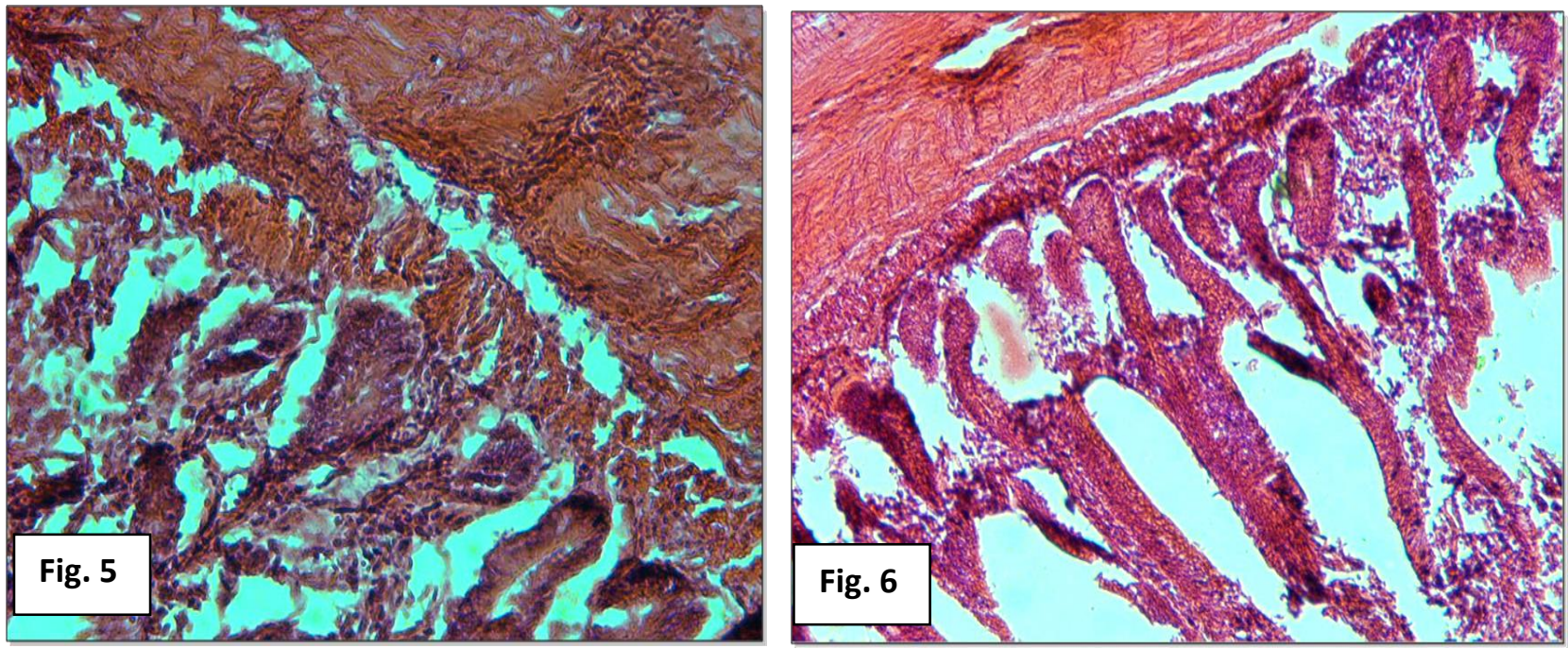

Fig.5-6. Section of infected intestine showing crypts, lumen of the glands is closed. Inflammatory cells are clearly visible $\mathrm{X} 100$.

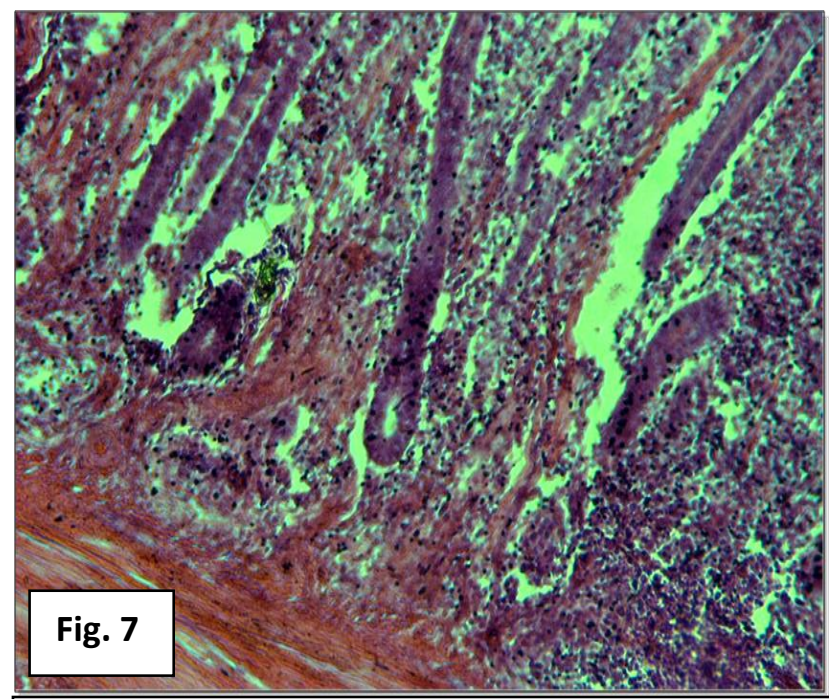

Fig.7. Section of infected intestine showing inflammatory cells throughout the section and at the base of crypts necrosis of the lamina propria is clearly visible X200. 


\section{References}

1. Food and Agricultural Organization (2006). High Bird Flu in Africa after outbreak in Nigeria, from: http:Ilwww.Fao.Org/newsoom/en/news/ 2006/1000226/index. html.

2. Obiora FC (1992). A guide to Poultry Production in the Tropics. 1st end. Acena Publishers. pp. 59-61:381, 382.

3. FAO Fostat www.fao.org (2000). Statical database of food and agriculture Organization of the United Nation. Rome Italy.

4. Ajala MK, Nwagu BI \& Otchere, EO (2007). Socioeconomics of free range poultry production among Agropastoral women in Giwa Local Government Area of Kaduna State, Nigeria, Nig. Vet J., 28:1118.

5. Whitmarsh S (1997). Parasitic Diseases (Internal). Poultry Science, Mississippi State University, Starkville, Miss, USA.

6. Mukaratirwa S \& Khumalo MP (2010). Prevalence of helminth parasites in freerange chickens from selected rural communities in Kwazulu-Natal province of South Africa.

7. Dube SP, Zindi J, Banga M \& Dube C (2010). A study of scavenging poultry gastrointestinal and ecto-parasites in rural areas of Matebelel and province, Zimbabwe. Int. J. Poult. Sci., 9(9): 911-915.

8. Puttalakshmamma GC, Ananda KJ, Prathiush PR, Mamatha GS \& Rao S (2008). Prevalence of gastrointestinal parasites of poultry in and around Banglore. Veterinary World, 1(7): 201-202.

9. Zubeda B (2012). Pathological changes in the intestine of chicken naturally infected with helminth parasites. Hyderabad, Sindh, Jamshoro, Pakistan. M.Phil thesis, Faculty of Natural Sciences, University of Sindh, Jamshoro, Pakistan.
10. Sayyed RS, Phulan MS, Bhatti WM, Pardeshi M \& Ali S (2000). Incidence of nematode parasites in commercial layers in Sawat. Pakistan Vet. J., 20(2): 107-108.

11. Shah AH, Anwar AH, Khan MN, Iqbal Z \& Qudoos A. (1999). Comparative studies on the prevalence of cestode parasites in indigenous and exotic layers at Faisalabad. Int. J. Boil 1(4): 277-279.

12. Zahida T, Fariha A \& Masood A (1999). Prevalence of cestode parasites of domestic fowl (Gallus gallus domesticus) Pakistan Vet. J., 19(3): 142-144.

13. Dharejo AM. (2006). Trematode parasites of birds of different feeding habits of Hyderabad District, Hyderabad, Sindh, Jamshoro, Pakistan. Ph.D. thesis, Faculty of Natural Sciences, University of Sindh, Jamshoro, Pakistan.

14. Soulsby EJL (1982) Helminths, Arthropods and Protozoa of Domesticated Animals, 7th Edition. London: Baillière Tindall.

15. Yamaguti S (1962). Systema Helminthum. Vol III. The nematodes of vertebrates. Part ii Interscience Publishers, London.

16. Zubeda B, Azra AS, Shakeel AM \& Bhojo M (2014). Prevalence of cestodes parasites in the intestine of local chicken (Gallus Domesticus) from Hyderabad, Sindh, Pakistan. Journal of Entomology and Zoology Studies 2(6): 301-303

17. Uho AC, Okafor FC, Odikamaoro OO, Onwe CS, Abarike MC. \& Elom, JN.(2013). Common gastrointestinal parasites of local chicken (gallus domesticus) slaughtered in some selected eatery ceynters in Abakaliki, Ebonyi State: Implication for meat quality International Journal of Development and sustainability 2(2): 1416-1422.

18. Medjouel, I \& Benakhla A (2013). Cestode parasites of chickens (Gallus gallus 
domesticus) in the North-Easternof Algeria. Int J Poult Science 12(11): 681-684.

19. Zahrani MR, Ashour AA \& Shobrak MY (2012). Tape worms of rock dove and domestic chicken in Taif area, Saudi Arabia. J. Egypt. Soc. Parasitol., 42(3): 507-13. 20. Radfar MH, Khedri J, Adinehbeigi K, Nabavi R \& Rehmani K (2012). Prevalence of parasites and associated risk factors in domestic pigeon (Columa livia domestica) and free range backyard chicken of Sistan region, east of Iran. Journal of Parasitic Diseases 36(2):220-225.

21. Hussen H, Chacka H, Deneke $Y$ \& Bitew M (2012). Gastrointestinal helminths are highly prevalent in scavenging chickens of selected districts of Eastern Shewa Zone, Ethiopia. Pakistan J Biol Science 15(6): 284-289.

22. Shahin, AM, Lebdah. M.A, Abu-Elkheir S.A \& Elmeligy, M.M. (2011). Prevalence of chicken cestodiasis in Egypt. New York Science Journal, 4 (9): 21-29.

23. Eslami A, Ghaemi $\mathrm{P} \&$ Rahbari $\mathrm{S}$ (2009). Parasitic infections of free range chickens from Golestan Province Iran. Iranin. Journal of Parasites 4(3): 1-4.

24. Zubeda B, Shaikh AA \& Khan MM (2012). Prevalence and pathology of Raillietina cesticillus in the intestine of local chicken (Gallus domesticus) in Sindh. Proceedings of Parasitology 53:43-51.

25. Sheikh T. Salam A. Khan \& Mir M (2009). Prevalence and Pathology of Amoebotaenia sphenoides in free ranging chicken of Kashmir Valley. The Internet Journal of Parasitic Diseases. Vol. 41.

26. Laxma Reddy, B \& Benarjee G (2014). Comparative liver histopathology of fresh water Murrels due to trematode, euclinostomum heterostomum. Biolife. 2(1): 396-399.

27. Bilqees FM, Khan A \& Muti-ur-Rehman (2004). Histopathology of the intestine of Kite (Milvus Migrus migrus) associated with Medioorhychus Nickoli. Proc. Parasitol., 37:37-43.

28.Muti-ur-Rehman (2004). Histopathology of the intestine of Eagle (Bustasur Teesa Franklin) Associated with Mediorhynchus fatimae. M.phil. thesis faculty of natural sciences University of Karachi Pakistan.

29. Snail NK, Asokan OK, John L \& Vijayan (2010). Pathological mainifestations of the acanthocephalan parasite, Tenuiproboscis sp. In the mangrove red snapper (Lutjanus argentimaculatus) (Forsskal, 1775), a candidate species for aquaculture from southern India. 